\title{
BUTCHERS' PREFERENCES FOR RABBIT MEAT; AHP PAIRWISE COMPARISONS VERSUS A LIKERT SCALE VALUATION
}

\author{
Zein KALLAS* \\ E-mail: Zein.kallas@upc.edu \\ Center for Agro-food Economy and Development \\ Polytechnic University of Catalonia \\ Casteldefells, Barcelona, SPAIN
}

\begin{abstract}
Our paper analyzes butchers preferences toward the attributes and levels for fresh rabbit meat. We compare results obtained from alternatives approaches of data collection: a) the traditional pair wise comparison of AHP $\left(\mathrm{AHP}_{1}\right)$ and $\left.\mathrm{b}\right)$ the direct valuation by mean of a 9 point likert scale transformed in a a subsequent step to estimate $\mathrm{AHP}\left(\mathrm{AHP}_{2}\right)$. The data used in this analysis was obtained from faceto-face questionnaires with butchers carried out during May-April 2010. The final sample consists of 50 butchers mainly located in Barcelona. Results obtained from the two approaches of data collection show similar rank of the preferred attributes and levels. However, the obtained weights from both approaches are not totally similar.
\end{abstract}

Keywords: AHP, likert scale, butchers preferences

\section{Introduction}

The AHP is a multi-criteria decision-supporting method that aims to decompose a complex decision problem in a hierarchy of smaller constituent sub-problems. In this context, consumers' decision toward products preference can be decomposed. AHP allow obtaining weights (w) for each attribute and level of a product in order to explain individual behavior in choosing their preferred one. The relative importance or weight $(w)$ for attribute $\left(A_{n}\right)$ and level $\left(L_{n . p}\right)$, where; $n(1, \ldots, N)$ is the number of attributes and $p(=1, \ldots, \boldsymbol{P})$ is the number of levels, are obtained from a $\mathrm{N} \times(\mathrm{N}-1) / 2$ pairwise comparisons (in the case of attributes) and $\mathrm{P} \times(\mathrm{P}-1) / 2$ (in the case of levels).

In this context of preference analysis, Likert (1932) developed the principle of measuring attitudes and preferences by asking people to respond to a series of statements about a topic, in terms of: agreement (From strongly Agree to strongly disagree), frequency (Always to never), importance (Very important to unimportant), quality (poor to excellent), likelihood (almost always true to almost never true) and so tapping into the cognitive and affective components of attitudes. Often five ordered response levels are used; although the seven or the nine levels are also applied. The Likert Scale is an ordered, one-dimensional scale from which respondents choose one option that best aligns with their view. Thus, using the likert as a scale in terms of importance allows obtaining the stated preference of attributes and levels of a product as in the case of the AHP.

Our paper seeks to compare results obtained from the abovementioned alternatives approaches of data collection: a) the traditional pairwise comparison of AHP $\left(\mathrm{AHP}_{1}\right)$ and b) a 9 point likert scale valuation collected in term of importance. To make a coherent comparison, we propose a transformation approach of the likert scale to approximate the Saaty pairwise comparison allowing estimating another AHP $\left(\mathrm{AHP}_{2}\right)$. The main advantage of the transformation of the likert scale valuation compared to the traditional pairwise comparison is the number of questions required to answers. While, in the latter the number needed is $\mathrm{N} \times(\mathrm{N}-1) / 2$ and $\mathrm{P} \times(\mathrm{P}-1) / 2$, in the former the

\footnotetext{
${ }^{*}$ Corresponding author
} 
required number match up the number of product attributes $(\mathrm{N})$ and levels $(\mathrm{P})$, reducing drastically the number of comparisons and alleviating the answering process. The data used for comparing both method of data collection in this analysis was obtained from face-to-face questionnaires with 50 butchers carried out during May-April 2010 to analyze their preferences for attributes and levels for fresh rabbit meat. Figure 1 shows a summary of the proposed methodological framework.

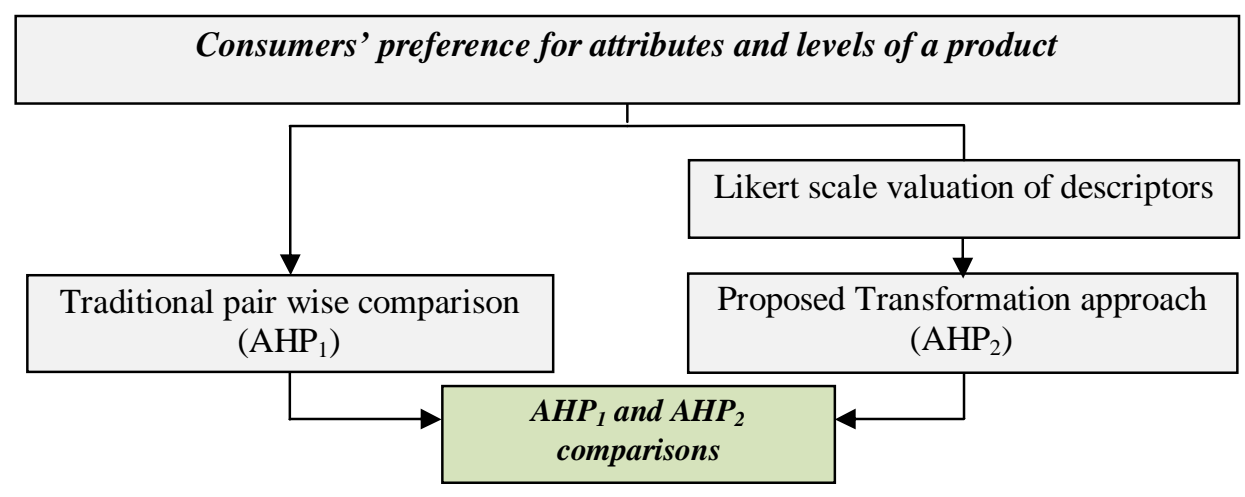

Figure 1: methodological framework of comparison procedure

\section{Methodology}

\subsection{The AHP from pairwise comparison $\left(\mathrm{AHP}_{1}\right)$}

Determining the most preferred alternative from a set of products is a decision problem where the top level of the hierarchy represents the individual product. It is decomposed into a predefined number of characteristics (attributes) on the second level and their corresponding levels on the third level as can be seen in Figure 2 where $A_{n}$ are the attributes and $L_{n . p}$ are the levels.

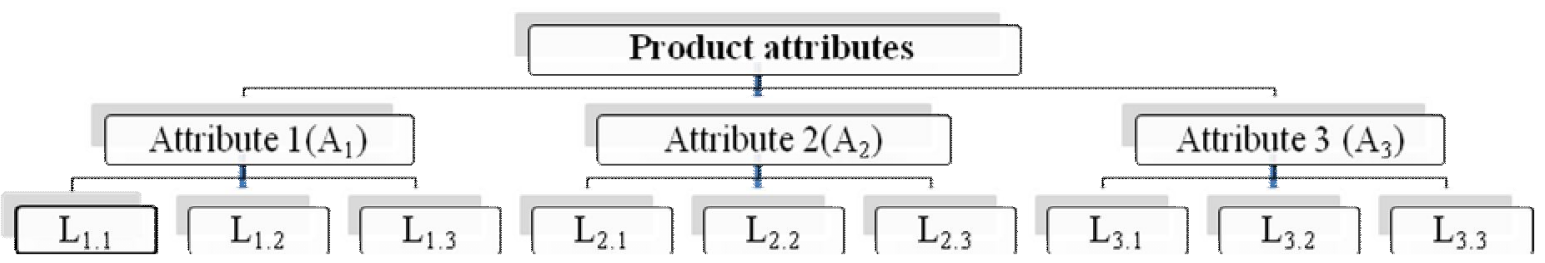

Figure 2: Hierarchical structure used to value product attributes and levels.

In order to implement the AHP, one needs to carry out a survey where individuals are asked to make two types of pairwise comparisons: a) a pairwise comparison of the levels within each attribute $\left(\mathrm{L}_{\mathrm{n} . \mathrm{p}}\right)$; and $b$ ) a pairwise comparison of the attributes $\left(A_{n}\right)$. First, the respondent has to indicate which of the two elements the respondent prefers. Then a nine-point scale is used to measure the strength of this preference by means of verbal judgments (Saaty, 1977; 1980). as shown in Table 1.

Table 1: AHP pairwise comparisons

\begin{tabular}{|c|c|c|c|c|c|c|c|c|c|c|c|c|c|c|c|c|}
\hline \multicolumn{9}{|c|}{$\mathbf{A}_{1}$} & \multicolumn{8}{|c|}{$\mathbf{A}_{n}$} \\
\hline 9 & 8 & 7 & 6 & 5 & 4 & 3 & 2 & 1 & 2 & 3 & 4 & 5 & 6 & 7 & 8 & 9 \\
\hline \multicolumn{8}{|c|}{$\mathbf{L}_{1.1}$} & \multicolumn{9}{|c|}{$\mathbf{L}_{\mathbf{n} . \mathbf{p}}$} \\
\hline 9 & 8 & 7 & 6 & 5 & 4 & 3 & 2 & 1 & 2 & 3 & 4 & 5 & 6 & 7 & 8 & 9 \\
\hline
\end{tabular}

To estimate the relative importance or weight $(w)$ for attribute $\left(\mathrm{A}_{\mathrm{n}}\right)$ and level $\left(\mathrm{L}_{\mathrm{n} . \mathrm{p}}\right)$, From the answers provided, a matrix with the following structure is generated for each individual $k(1, \ldots, \mathrm{K})$ and is known as a Saaty matrix. 


$$
S_{k}=\left[\begin{array}{cccc}
a_{11 k} & a_{12 k} & \ldots & a_{1 j k} \\
a_{21 k} & a_{22 k} & \ldots & a_{2 j k} \\
\ldots & \ldots & a_{i j k} & \ldots \\
a_{i 1 k} & a_{i 2 k} & \ldots & a_{N N k}
\end{array}\right]
$$

where $a_{i j k}$ represents the value obtained from the pairwise comparison between attribute/level $i(i \in \mathrm{N} /$ $i \in \mathrm{P})$ and attribute/level $j ;(j \in \mathrm{N} / j \in \mathrm{P})$ for each individual $k$. If perfect consistency in preferences hold for each decision-maker, it should also hold that $a_{i h k} \times a_{h j k}=a_{i j k}$ for all $i, j$ and $h(h \in \mathrm{N} / h \in \mathrm{P})$. This condition implies that values given for pairwise comparisons represent weights given to each objective by a perfectly rational decision-maker $a_{i j k}=w_{i k} / w_{j k}$ for all $i$ and $j$. Under such circumstances, $K$ weights $\left(w_{N k}\right)$ for each attribute and $K$ weights $\left(w_{P k}\right)$ for each level can be easily determined from the $\mathrm{N}(\mathrm{N}-1) / 2$ values and $\mathrm{P}(\mathrm{P}-1) / 2$ values for $a_{i j k}$ respectively. However, perfect consistency is seldom present in reality, where personal subjectivity plays an important role in the pairwise comparison.

In Saaty matrices where some degree of inconsistency is present, alternative approaches have been proposed to estimate the weight vector that is better able to represent the decision-maker's real weight vector. Saaty $(1980 ; 2003)$ proposed two options as the accurate estimate of real weights: the geometric mean and the main eigenvector. Other authors have proposed alternatives based on regression analysis (Laininen and Hämäläinen, 2003) or goal programming (Bryson, 1995). As all criteria meet the requirements to estimate the above-mentioned weights, we choose the geometric mean (Aguarón and Moreno, 2000; Kallas, et al., 2007). Using this approach, weights assigned by subject to each attribute and level are obtained using the following expression:

$$
w_{i k}=\sqrt[N, P]{\prod_{i=1}^{i=N, P} a_{i j k}}
$$

$$
\forall i, k
$$

\subsection{The AHP from Likert scale comparisons $\left(\mathrm{AHP}_{2}\right)$}

Following the alternative approach of likert scale to collect data first we realize a direct valuation of attributes and levels using a nine-point likert scale; where "1" mean that the attribute is "not important" in the decision of buying the product and " 9 " mean it is "very important" as can be seen in Table 2.

Table 2: direct valuation of attributes and level by likert scale

\begin{tabular}{c|ccccccccc}
\hline Attributes and levels & \multicolumn{8}{|c}{ (1: Non important, 5: Indifferent } & 9: Very important) \\
\hline$A_{n}$ & 1 & 2 & 3 & 4 & 5 & 6 & 7 & 8 & 9 \\
\hline$L_{n . p}$ & 1 & 2 & 3 & 4 & 5 & 6 & 7 & 8 & 9 \\
\hline
\end{tabular}

In a subsequent step, the result of each valuation score $(S c)$ obtained from the abovementioned likert scale is transformed to simulate a pairwise comparison as follow:

Let suppose that the score value " $S c$ " for individual $k$ obtained from the likert scale valuation for a product descriptors $i$ (i.e. attributes or levels) is $S c_{i k}$ and the score value for another descriptors $j$ is $S c_{j k}$. Both scores are measured on the same ordered, one-dimensional and continuous scale. Therefore, the difference between scores $\left(S c_{i k}-S c_{j k}\right)$ allow to approximate the difference of "relative importance" between the measured descriptors. As a result, scores difference can be transformed to simulate the judgment $\left(a_{i j}\right)$ of the traditional AHP pairwise comparisons between descriptors $i$ and $j$ as follow:

$$
\hat{a}_{i j}=\left|S c_{i k}-S c_{j k}\right|+1
$$

The estimated judgments by the transformation approach are used later to estimate the relative weights $(w)$ of attribute $\left(\mathrm{A}_{\mathrm{n}}\right)$ and level $\left(\mathrm{L}_{\mathrm{n} . \mathrm{p}}\right)$, following the usual AHP estimation procedure. For instance, if $S c_{i k}$ of the descriptor $i$ for individual $k$ is 8 and the $S c_{j k}$ of the descriptor $j$ for individual $k$ is 
6 , then the transformation approach of the paired comparisons between $i$ and $j$ is $\hat{a}_{i j}=\left|S c_{i k}-S c_{j k}\right|+1$ $=|6-8|+1=3$.

\section{Empirical application}

For the empirical application we evaluate the stated preferences of butchers for rabbit meat product in Barcelona. The data used in this analysis was obtained from face-to-face questionnaires with butchers carried out during May-April 2010. Each questionnaire solicits extensive information on their characteristics, attitudes and perceptions toward rabbit meat. The final sample consists of 50 butchers mainly located in Barcelona. To mitigate the order effect, we follow a design based on ordering change, both within and between the two approaches of data collection as advised by Charzan (1994). We split our sample into four sub-samples, generating four versions of the survey differentiated by different orders between the pairwise comparisons and likert scale.

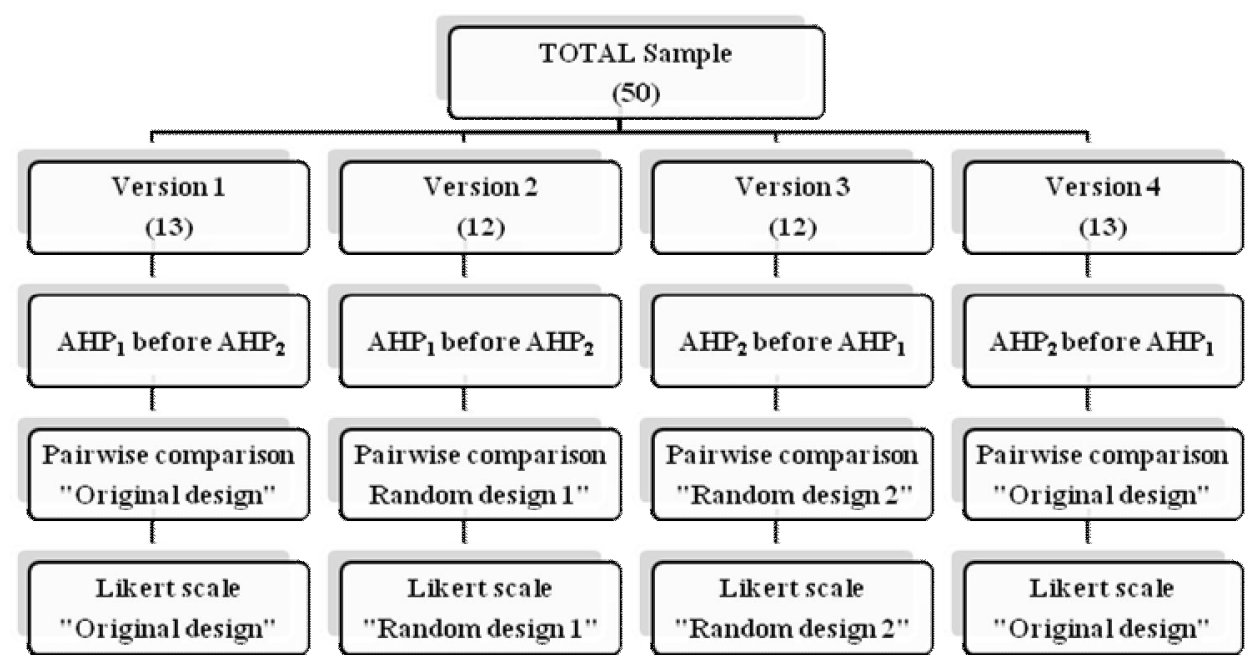

Figure 2: Followed design to mitigate order effect within and between methods

In the empirical application the first step is to clearly define the main attributes that butchers take into consideration when purchasing rabbit meat. We first rely on prior research performed on rabbit meat preferences (Hoffman et al., 1992, Mclean-Meyinsse, 2000, Hoffman, et al., 2004, Kalio et al., 2008, Kallas et al., 2011) and a focus group comprised of university lecturers in the field of marketing. The final set of attributes included is: origin, format, brand and price (Table 3 )

Table 3: Attributes and levels rabbit meat preference for butchers

\begin{tabular}{l|l}
\hline Attributes & \multicolumn{1}{|c}{ Levels } \\
\hline Origin $(\mathbf{A 1})$ & Catalan supplier (regional), Spanish supplier (national) and Foreign supplier (international). \\
\hline Brand $\left(\mathbf{A}_{3}\right)$ & Unbranded, Commercial brand and Quality brand \\
\hline Format $\left(\mathbf{A}_{2}\right)$ & Boneless rabbit meat, Pieced rabbit meat and Entire rabbit meat \\
\hline Price & Generic attribute without levels. \\
\hline
\end{tabular}

\section{Results}

Results obtained from the two approaches of data collection (the traditional pairwise comparisons and the likert scale valuation and its posterior transformation) show similar rank of the preferred attributes and levels. In both methods the most important attribute is the price that has the highest weight, followed by the format, brand and origin. However, as can be seen in the constructed hierarchy in Figure 3, the obtained weights from both approaches are not totally similar. For instance, the weight of the price attribute from the $\mathrm{AHP}_{1}$ is 0.359 while it is 0.290 in the $\mathrm{AHP}_{2}$. Also for the origin, brand 
and format attributes the obtained values are $0.102,0.169$ and 0.295 for the $\mathrm{AHP}_{1}$ and, $0.1555,0.248$ and 0.273 for the $\mathrm{AHP}_{2}$ respectively).

Analyzing the weights of levels within each attribute both methods report similar weights with small differences. All ranks of levels is similar for all the analyzed attributes. Thus within the origin attributes the preferred level is for Catalan, followed by Spain and Foreign origin of the meat. For the brand attribute, the most preferred level is for quality brand, commercial and unbranded product. Finally, the butchers prefer entire rabbit meat compared to the pieced and boneless.

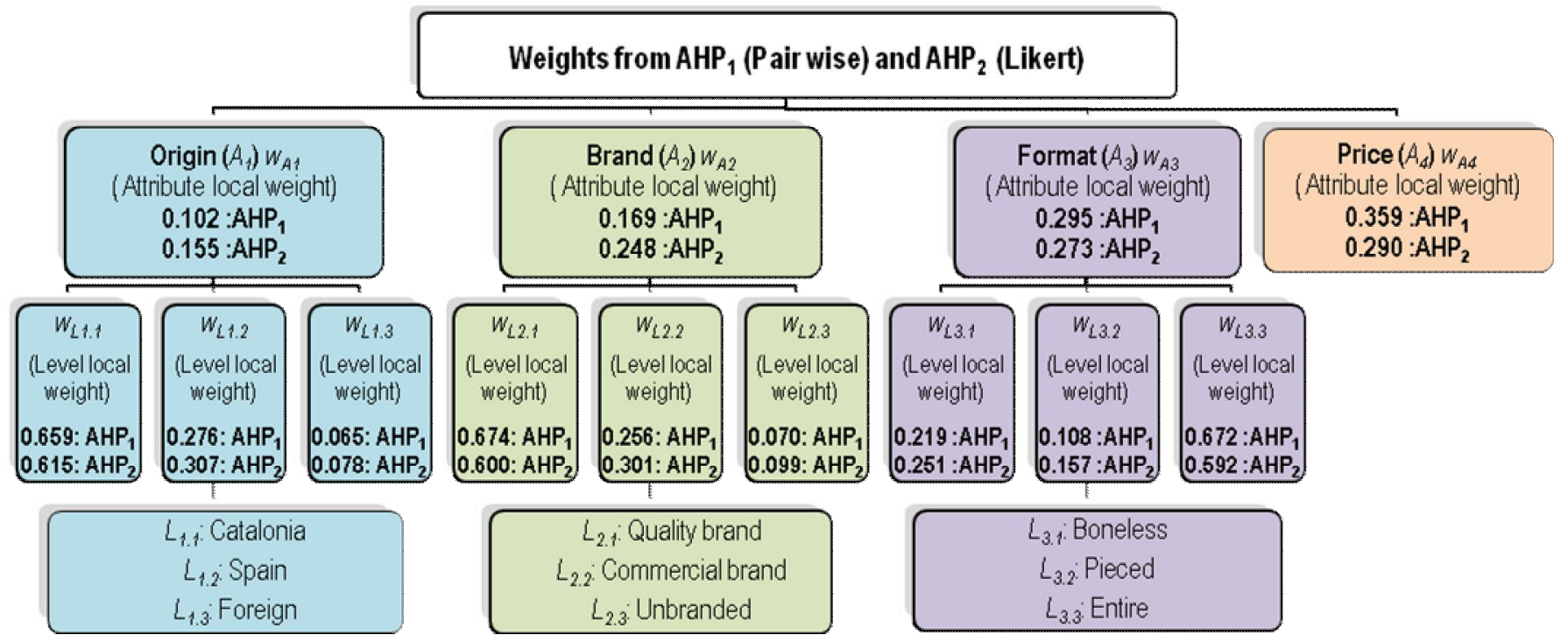

Figure 3: Results of the descriptors' weights between $\mathrm{AHP}_{1}$ and $\mathrm{AHP}_{2}$

Analyzing quantitatively the difference between weights from both approaches of data collection in valuating attributes and levels, results in Table 4 show the presence in some cases of statistically significant difference. However, the differences between weights from $\mathrm{AHP}_{1}$ and $\mathrm{AHP}_{2}$ are small and in general oscillate from $1 \%$ to $8 \%$. However, in some cases the magnitude of the difference is statistically significant. With the exception of the format attribute all differences are significantly different. In addition, with the exception of the origin levels, value obtained from $\mathrm{AHP}_{1}$ for unbranded and Boneless levels are higher than those obtained from $\mathrm{AHP}_{2}(7.36 \%$ and $8.05 \%$ respectively). However, $\mathrm{AHP}_{1}$ shows low value of Commercial brand and Pieced levels compared to $\mathrm{AHP}_{1}(-4.48 \%$ and $-4.85 \%$ respectively).

Table 4: Weights of attributes and levels

\begin{tabular}{|c|c|c|c|c|c|c|c|}
\hline & & AHI & air-wise) & $\mathbf{A H}$ & (Likert) & Diffe & ence \\
\hline \multirow{4}{*}{ Origin } & Catalan (regional) & \multirow{4}{*}{$\begin{array}{c}10.25 \% \\
(2.03)\end{array}$} & $65.89 \%(2.43)$ & \multirow{4}{*}{$\begin{array}{c}15.49 \% \\
(1.16)\end{array}$} & $61.48 \%(1.54)$ & \multirow{4}{*}{$-5.25 \% * *$} & $4.41 \%$ \\
\hline & Spanish (national) & & $27.63 \%(2.01)$ & & $30.68 \%(1.39)$ & & $-3.05 \%$ \\
\hline & Foreign (international). & & $6.47 \%(0.17)$ & & $7.83 \%(0.17)$ & & $-1.36 \%$ \\
\hline & Total & & 100.00 & & 100.00 & & -- \\
\hline \multirow{4}{*}{ Brand } & Unbranded, & \multirow{4}{*}{$\begin{array}{c}16.86 \% \\
(2.79)\end{array}$} & $67.40 \%(2.67)$ & \multirow{4}{*}{$\begin{array}{c}24.84 \% \\
(1.80)\end{array}$} & $60.04 \%(1.92)$ & \multirow{4}{*}{$-7.97 \% * * *$} & $7.36 \% * *$ \\
\hline & Commercial brand & & $25.59 \%(2.14)$ & & $30.07 \%(1.28)$ & & $-4.48 \% * *$ \\
\hline & Quality brand & & $7.01 \%(0.31)$ & & $9.89 \%(0.30)$ & & $-2.88 \%$ \\
\hline & Total & & 100.00 & & 100.00 & & -- \\
\hline \multirow{4}{*}{ Format } & Entire & \multirow{4}{*}{$\begin{array}{c}29.52 \% \\
(3.50)\end{array}$} & $21.93 \%(1.94)$ & \multirow{4}{*}{$\begin{array}{c}27.30 \% \\
(1.51)\end{array}$} & $25.13 \%(1.31)$ & \multirow{4}{*}{$2.22 \%$} & $-3.20 \%$ \\
\hline & Pieced & & $10.84 \%(2.14)$ & & $15.69 \%(1.99)$ & & $-4.85 \% * *$ \\
\hline & Boneless & & $67.23 \%(3.87)$ & & $59.18 \%(2.76)$ & & $8.05 \% * * *$ \\
\hline & Total & & 100.00 & & 100.00 & & -- \\
\hline
\end{tabular}




\begin{tabular}{l|l|l|l}
\hline \multirow{2}{*}{ Price } & $\begin{array}{c}35.88 \% \\
(3.10)\end{array}$ & $\begin{array}{l}28.96 \% \\
(2.23)\end{array}$ & $6,92 \% * *$ \\
\hline TOTAL & $100.00 \%$ & $100.00 \%$ & \\
\hline
\end{tabular}

Significance levels: ***p $<0.01 ; * * \mathrm{p}<0.05 ;{ }^{*} \mathrm{p}<0.10$.

\section{Conclusions}

Using the likert scale to estimate the relative importance of attributes and levels in the decision of individual to buy products can be a valid data collection approach. Our proposed approach to transform the scale score to a judgment of a pairwise comparison

It would be also relevant to compare results using different number of point scale. In this context it is relevant to mention that Dawes (2008) found that a 5 or 7 point scale may produce slightly higher mean scores compared to those obtained from a 10 point scale. The main advantage of the transformation of the likert scale valuation compared to the traditional pairwise comparison is the number of questions required to answers. While, in the latter the number needed is $\mathrm{N} \times(\mathrm{N}-1) / 2$ and $\mathrm{P} \times(\mathrm{P}-1) / 2$, in the former the required number match up the number of product attributes $(\mathrm{N})$ and levels $(\mathrm{P})$, reducing drastically the number of comparisons and alleviating the answering process. Results show similar rank of the preferred attributes and levels from both methods. However significant differences are found between weights of some attributes and levels. More efforts are needed to obtain more empirical evidence of this comparison approach.

\section{REFERENCES}

Aguarón, J. and Moreno-Jiménez, J.M. (2000) Stability intervals in the analytic hierarchy process. European Journal of Operational Research, 125, 114-133.

Bryson, N. (1995) A goal programming method for generating priority vectors. Journal of the Operational Research Society, 46, 641-648.

Charzan, K. (1994) Three kinds of order effects in choice-based conjoint analysis. Marketing Letters, 5(2), 165-172.

Hoffman, I.; Kobling, S.; Stier, C-H and Gall, C. (1992), "The potential of rabbit meat marketing in bobo-Dioulasso, Burkina Faso", Livestock Research for rural development, Vol. 4, No. 1, pp. 21-29.

Hoffman, L.C.; Nkhabutlane, P.; Schutte, D.W. and Volsoo, C. (2004), "Factors affecting the purchasing of rabbit meat: A study of ethnic groups in the Western Cape", Journal of Family Ecology and consumer Sciences, No.32, pp.26-35.

Kallas, Z., Gómez-Limón, J.A. and Barreiro, J. (2007). Decomposing the value of agricultural multifunctionality: Combining contingent valuation and the analytical hierarchy process. Journal of Agricultural Economics, 58(2), 218 - 241.

Kallas, Z.; Lambarraa, F. and Gil, J.M. (2011), "A stated preference analysis comparing the Analytical Hierarchy Process versus Choice Experiments", Food Quality and preferences, Vol. 22, pp. 181-192.

Likert, R. (1932). A Technique for the Measurement of Attitudes, Archives of Psychology, No.140

Saaty, T. (1977) A scaling method for priorities in hierarchical structures. Journal of Mathematical Psychology, 15(6), 234-281.

Saaty, T. (1980) The analytic hierarchy process. New York: McGraw-hill.

Saaty, T. (2003) Decision-making with the AHP: Why is the principal eigenvector necessary?. European Journal of Operational Research, 145(1), 85-91. 